\title{
The Roles and Challenges of Cloud Computing to Accounting System of Vietnamese Enterprises in the Fourth Industrial Revolution
}

\section{Thao Phan Huong}

Department of Accounting - Auditing, Thuong Mai University, Cau Giay District, Hanoi, Vietnam Email: thaoktcb@gmail.com

\author{
Article History \\ Received: June 15, 2020 \\ Revised: September 12, 2020 \\ Accepted: September 26, 2020 \\ Published: September 30, 2020 \\ Copyright (C) 2020 ARPG \& \\ Author \\ This work is licensed under the \\ Creative Commons Attribution \\ International \\ (5) (1) CC BY: Creative \\ Commons Attribution License \\ 4.0
}

\begin{abstract}
In the context of the 4.0 revolution, technology applications, especially cloud computing will have strong impacts on all areas, including accounting systems of enterprises. Cloud computing contributes to helping the enterprise accounting apparatus become compact, help automate the input process, improve the accuracy of the input data. Besides, the issur of accounting, reporting, risk control and information security also became better, contributing to improving the effectiveness of accounting. However, besides the positive impacts, businesses also face many difficulties in deploying and applying cloud computing. However, this application requirement will become an inevitable trend contributing to improving the operational efficiency of enterprises. To promote this process requires from the State as well as businesses themselves must have awareness and appropriate decisions. Breakthroughs in information technology have dramatically changed the accounting industry and the creation of financial statements. The Internet and the technologies that use the power of the Internet are playing an important role in the management and accounting activities of businesses - who always tend to be ready to receive and use public innovations technology in collecting, storing, processing and reporting information.
\end{abstract}

Keywords: Cloud computing; Accounting; Enterprise; The fourth industrial revolution.

\section{Introduction}

Today, with the impact of the 4.0 industry revolution and the growth of big data, the spread of internet-based applications has created the appropriate context for the emergence of a number of new technology concepts such as Cloud Computing (CC), Internet of Things (IoT), big data (Big Data) and artificial intelligence (AI). In particular, cloud computing is the basic platform, any application about AI, IoT or Big Data needs the underlying infrastructure - the Cloud - to operate. The Cloud computing emerges as a new computing paradigm which aims to provide reliable, customized and QoS guaranteed dynamic computing environments for end-users. In this paper, we study the Cloud computing paradigm from various aspects, such as definitions, distinct features, and enabling technologies. This paper brings an introductional review on the Cloud computing and provides the roles and challenges of Cloud computing technologies to accounting system in enterprises.

Cloud computing is understood as "a computing resource procurement and deployment model that allows an organization to obtain its computing resources and applications from any location via an Internet connection" (Chan et al., 2012). According to Abdullah Mohammad Al-Zoubi (2017) "Cloud computing is a term used to describe the use of computer technology based on the Internet".

The US National Institute of Standards and Technology (US NIST), again, introduced the concept of cloud computing as "a model to allow online access to shared resources (for example, networks, servers, storage devices, applications, and services) conveniently and on demand. These resources can be provided quickly or recalled with minimal administration costs or minimal interaction with the service provider."

Thus, cloud computing can be interpreted as a computing model using computer technologies and is developeed based on the Internet, which is the use of computational resources that can change according to the needs, provided as a service from providers with payment per use. Enterprises can access to any resource that exists in the "cloud" at any time and from anywhere through the Internet. 


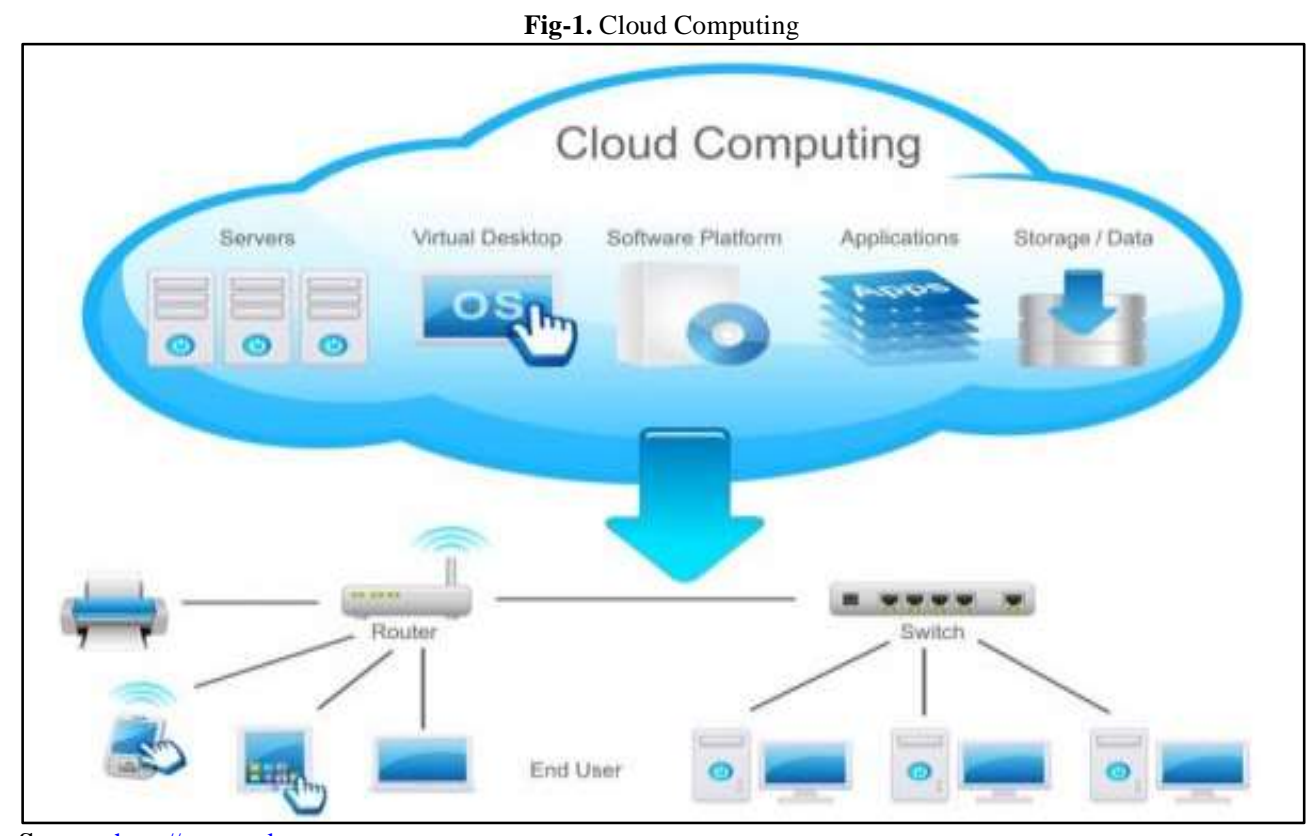

Source: http://www.zdnet.com

If with the traditional model, businesses will buy software installed and used on site to serve the activities such as management, accounting, etc. This method creates a problem: restrictions on data sharing and regarding the decentralization and responsibility of the members. On the contrary, cloud computing applications with features on servers provide online services that enable users to access anytime, anywhere. The use of software installed on site on personal computers and cloud computing are fundamentally different, as follows:

Table-1. Comparison between using on-site software and cloud computing

\begin{tabular}{l|l|l}
\hline & On-site softwares & Cloud Computing \\
\hline Investment costs & $\begin{array}{l}\text { Large investment is required to } \\
\text { purchase hardware, software, servers } \\
\text { and training IT staff to manage the } \\
\text { system. Besides that is the requirement } \\
\text { for upgrades and maintenance. }\end{array}$ & $\begin{array}{l}\text { Low initial investment because no physical } \\
\text { installation is required, only necessary for } \\
\text { software development and internet access. } \\
\text { Upgrades and maintenance are done by the } \\
\text { service provider. }\end{array}$ \\
\hline $\begin{array}{l}\text { Fess flexibility in the process of } \\
\text { working and upgrading due to } \\
\text { infrastructure requirements and staff } \\
\text { capabilities }\end{array}$ & $\begin{array}{l}\text { More flexibility because it can be accessed } \\
\text { from any browser. And because data in the } \\
\text { cloud is stored externally, access can easily } \\
\text { be provided to third parties. }\end{array}$ \\
\hline becaurity & $\begin{array}{l}\text { Can be designed according to the the secure than the cloud } \\
\text { organization's business needs }\end{array}$ & $\begin{array}{l}\text { Considered safer than using on-site software } \\
\text { because cloud providers keep data secure } \\
\text { through encrypted solutions, firewalls, } \\
\text { backups, etc. }\end{array}$ \\
\hline Features & $\begin{array}{l}\text { Operated on a large scale and is not likely to } \\
\text { be customized by a specific business. }\end{array}$ \\
\hline
\end{tabular}

Source: (Ashok Kumar and Pragya, 2018)

\subsection{Cloud Computing Service Models Include}

Software as a Service (SAAS): This is a service that provides software applications via Internet for users upon request. SAAS providers can host the application on their server or download the application to a client device, then disable it after the end of the term. The requested function can be controlled internally to share the copyright of a third application provider.

Platform as a Service (PAAS): This is a service available for developers to create mobile applications without setting up a server or server infrastructure, database or network required for development. Service providers will provide businesses with server systems and operating systems for users to deploy.

Infrastructure as a Service (IAAS): This is a service provided by a cloud provider in which the infrastructure can be rented - which means businesses will rent the whole infrastructure services (line systems, networks, lines, servers, etc.) of cloud service providers. IAAS allows users to access remote computer infrastructures, with the aim of enabling the expansion of that person's own system by using this powerful virtual infrastructure. 


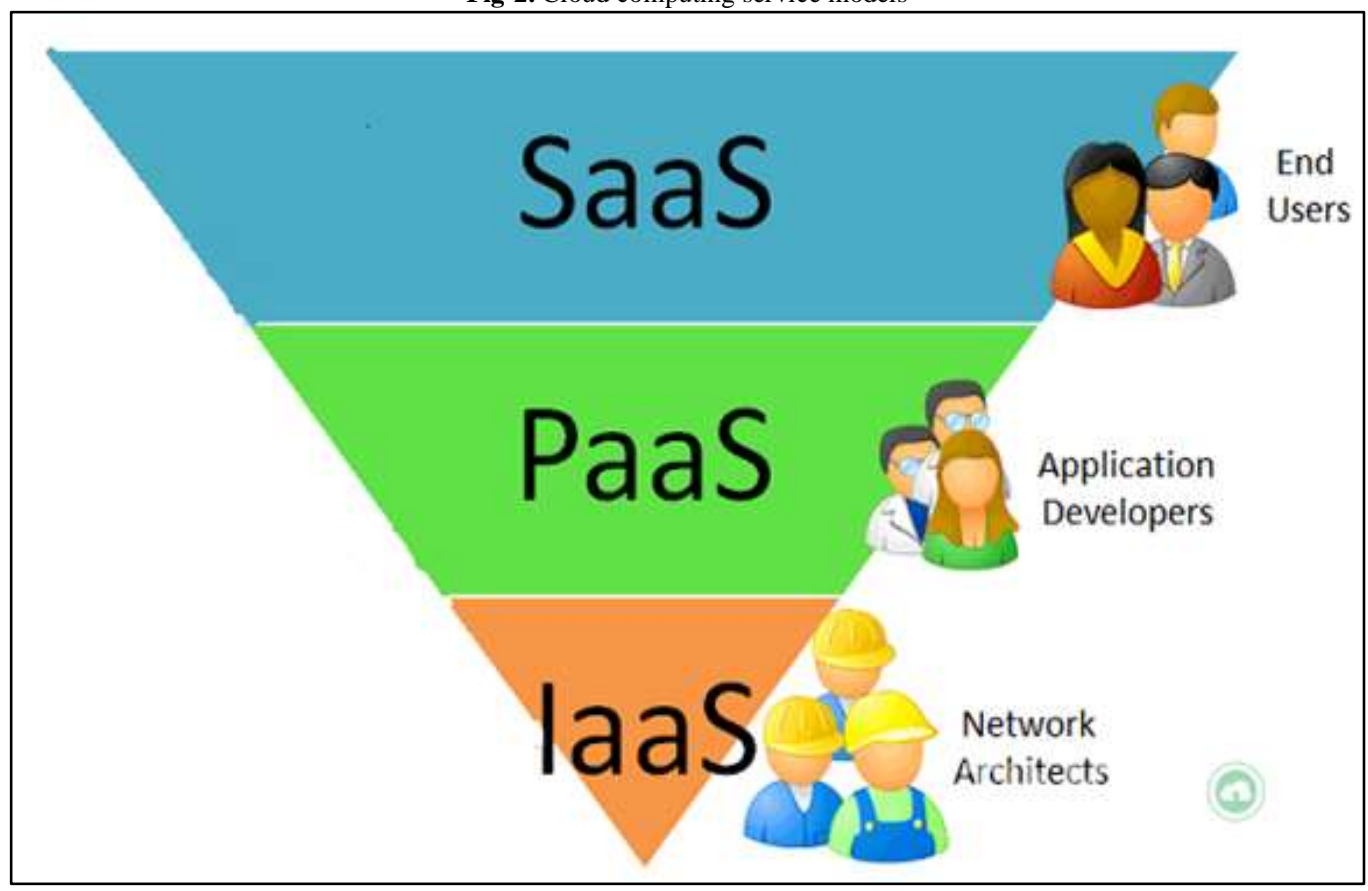

Source: http://www.zdnet.com

\subsection{On that Basis Cloud Computing is deployed into 3 Types}

There are three types of cloud computing deployment models are: Private Cloud, Public Cloud and Hybrid Cloud as shown in Fig 3.

Private cloud (Internal cloud): is operated for a single enterprise. It can be installed in the data center of that organization. In particular, services and infrastructure are maintained on a private network and are only accessible to the parties involved in that organization. This is an inevitable trend for businesses to optimize information technology infrastructure.

Public cloud (External cloud): is provided to the general public or a large-scale industry and is owned by a cloud service business organization. The network, server, or any computer will be made available to users by managing accounts in the cloud service providers' web browsers. All users have the right to sign up for the service and the level of use depends on the policy of the provider and the provider's charges.

Hybrid cloud (Mixed cloud): combines public cloud and private cloud. It allows businesses to exploit the strengths of each model as well as provide optimal usage methods for users. These "clouds" are usually created by the enterprise and the management will be split between the enterprise and the public cloud provider.

Fig-3. Three types of Cloud Computing Deployment Models

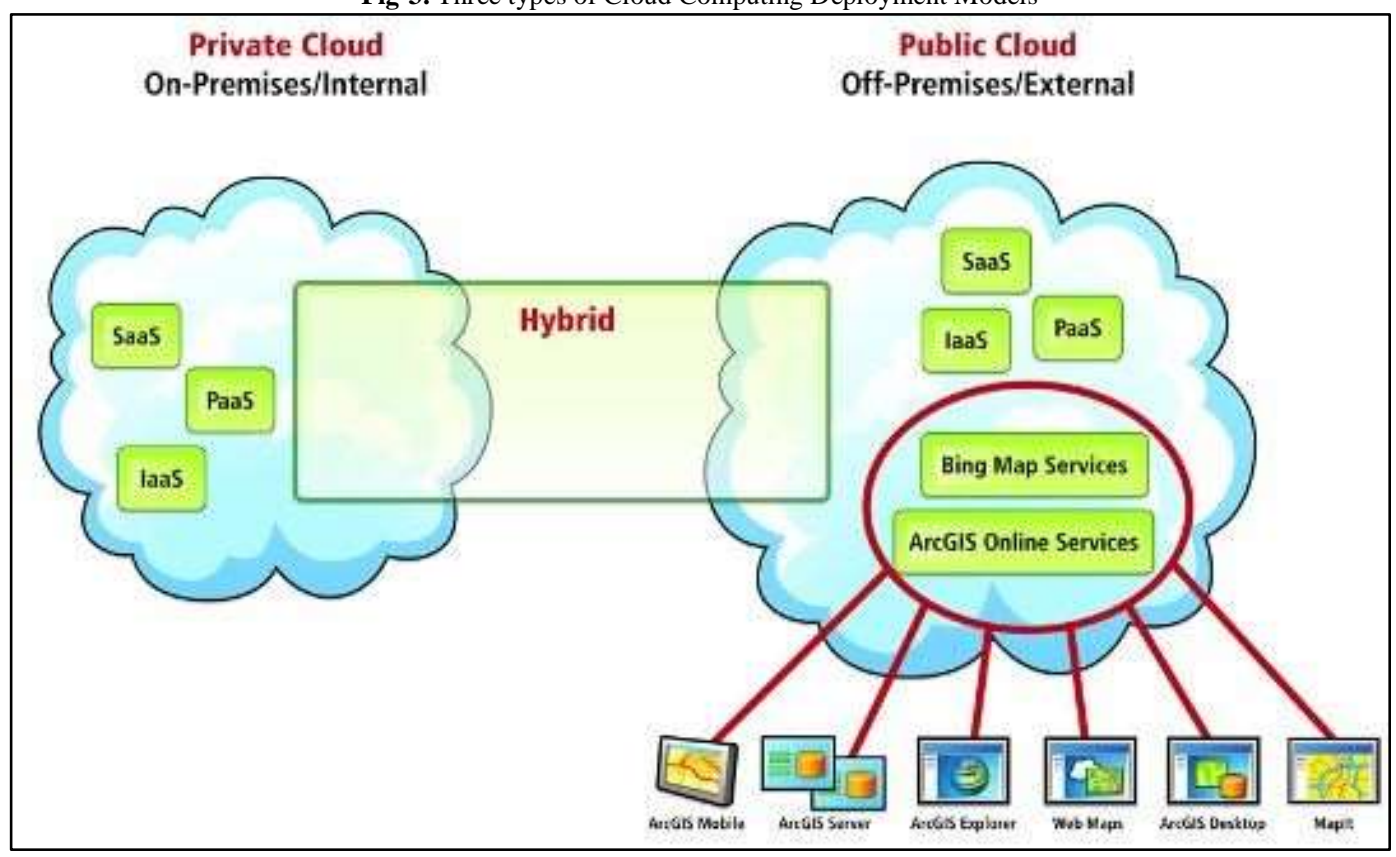

Source: http://www.zdnet.com 
In short, cloud computing is a method of managing, storing and processing data via the Internet instead of onsite servers or personal computers for easy access to stakeholders. It allows users and businesses to store and process their data in a privately owned cloud or on a third-party server to make data access more convenient and reliable.

\subsection{Cloud Computing Features}

Cloud computing brings an array of new features compared to any other computing paradigms. There are briefly described in this section.

Scalability and On-Demand Service: Cloud computing provides resources and services for users on demand. The resources are scalable over several data centers.

Quality of Service (QoS): Cloud computing can guarantee QoS for users in terms of hardware or CPU performance, bandwidth, and memory capacity.

User-Centric Interface: Cloud interfaces are location independent and they can be accessed by well established interfaces such as Web services and Web browsers.

Autonomous System: Cloud computing systems are autonomous systems managed transparently to users. However, software and data inside clouds can be automatically reconfigured and consolidated to a simple platform depending on user's needs.

Pricing: Cloud computing does not require up front investment. No capital expenditure is required. Users may pay and use or pay for services and capacity as they need them.

\section{The Roles of the Cloud Computing for the Accounting System}

Cloud computing in the field of accounting originates from the information society, in the context of the 4.0 industrial revolution, businesses are ready to switch from the use of traditional data processing and storage methods to web-based solutions. In the inevitable development trend of the technology revolution, cloud computing has had strong impacts on enterprise accounting. Through cloud computing, it performs accounting functions via the Internet, no need to install software in local servers, all accounting functions will be performed by users by logging in the cloud. Cloud service providers provide remote servers or applications for a fee and online access so that businesses can manage and maintain accounting data. Data is stored in the cloud over time, ensuring the reliability of the data to be accessed and different users can access the data at the same time, helping the process of exchanging and linking information quickly, fast and efficient.

When financial information is provided in a timely manner through sharing and receiving information in the cloud, decision making is enhanced throughout the organization (Chan et al., 2012). All information is stored and all transactions are carried out in the cloud, during operation, only a laptop with modem or smartphone, a company can continue its business, accounting department can still operate effectively.

When doing cloud accounting, this system helps reduce the burden of data entry and other manual reporting tasks through cloud accounting solutions offered by service providers and in the case of fluctuations, the flexibility of cloud-based services will be able to make adjustments that correspond to customer needs and business requirements. Businesses regardless of size when using cloud computing will only have to pay for the usage but not have to pay a lot of investment costs for hardware, servers, thus will contribute financial support for the company in growth stages - this is especially meaningful in the period when businesses are in trouble.

According to Shaban and Ali (2014), implementing cloud-based accounting has much more positive characteristics than traditional accounting models because the cloud computing techniques integrated with the Accounting applications help improve the efficiency of accounting in data analysis, information control and assist in the decision-making process on a regular and continuous basis.

Ebenezer et al. (2014), suggested that cloud computing can be successfully applied to accounting purposes. Although cloud accounting in reality may not seem too different from accounting on a computer based on on-site software, cloud computing has many ways to enhance the efficiency of accounting work. The objective of all accounting information systems is to collect and store data about activities and transactions; process data for decision making; and provide adequate controls to protect an organization's assets. The benefit of cloud computing gives everyone the opportunity to be mobile with everything they do. Cloud accountants can do mobile accounting by approving transactions; payment authorization; enter financial data; create financial statements; ... anywhere through importing and sending to the "cloud", then return to users as required, without performing on a desk computer in the traditional way.

This mobile feature will bring accountants benefits through timely information sharing, helping to speed up decision making. Moreover, financial data can be stored at relatively cheaper costs without investing in infrastructure and maintenance costs.

With the above characteristics, cloud computing has positive roles to the VietNamese enterprise accounting system, specifically as follows:

\subsection{Firstly the Role of Cloud Computing in Organizing the Accounting Department}

When studying the impact of cloud computing on business accounting, author Abdullah Mohammad Al-Zoubi (2017) said that when applying cloud computing to accounting activities, enterprises can organize an accounting system quickly because not affected by geographic location and equipment, employees and stakeholders have access to applications via computers and mobile devices from anywhere through the Internet access. Thus, for businesses of different sizes, including large enterprises, corporations with offices and offices located in different areas and 
locations, only one accounting department is required at any location. It is possible to manage and perform accounting work for the whole enterprise through processing, analyzing and accessing data from the "cloud" instead of fixed software located on the desk computers at a certain location.

In addition, when cloud computing applications buy and sell information directly from customers and are automatically processed through cloud computing systems without the need for direct transactions - this not only contributes to reducing the number of enterprise employees in general, but the number of accountants can also be reduced. Information is set up once and shared directly with parties inside and outside the enterprise, ensuring the transparency of information during trading activities between the parties. In addition, the application of cloud computing helps to save costs on hardware and software during deployment and installation, and businesses can add new, simple and easy-to-use softwares.

\subsection{Secondly the Role of Cloud Computing in the Accounting Information System}

For accounting documents, when performing cloud accounting, documents can be scanned and entered into the system automatically then accountants can check and confirm entries. This helps to save costs during processing because the invoice scan can be done simply and in bulk by the enterprise itself. In addition, cloud-based accounting systems provide tools to eliminate the risks of inaccuracy and inconsistencies of data that systems run by other models create.

For accounting books, most cloud platforms create information through a collective general ledger, which makes it easier to audit and track historical data.

For accounting reports, the quality of information on the accounting reports will be improved thanks to the timeliness and accuracy with the support of processing and reporting over time. Cloud users can receive financial statements provided by the system at any time according to the authority granted (Abdullah Mohammad Al-Zoubi, 2017).

\subsection{Thirdly the Role of Cloud Computing in Backing up and Storing Accounting Data}

With cloud computing, all important accounting files and data are accessible from any device and any location with an Internet connection, with no limit on the ability to work and complete. In addition, businesses will not have to back up data regularly to protect against system errors or unforeseen disasters because these will never happen to the cloud. In accounting, in many cases, enterprises will have to analyze big data for management but sometimes, companies have more data than the management capabilities of on-site computer solutions, now they can use cloud computing to manage and process this large amount of information.

In addition to these positive effects, cloud computing technology can be combined with applications based on ERP, AI, Blockchain, etc to meet the requirements of input data processing, providing output information quickly, promptly and transparently, contributing to improving the efficiency of accounting organization in enterprises.

In general, through the research results from the authors, it showed the positive effects when applying cloud computing to accounting - which helps organize accounting in enterprises more effectively, input and output data can be automatically and easily shared for related subjects, contributing to increasing transparency and quality of accounting information.

\section{Challenges for Vietnamese Enterprises When Applying Cloud Computing}

In the context of integration and the strong development of the 4.0 technology revolution today, Vietnam cannot stand outside that development trend. IBM was the first unit in our country to launch a cloud computing center in 2008, followed by a number of other companies providing cloud services, but most focused on narrow market segments, such as QTSC, VNTT, Prism, Exa, HostVN, MOS, Biaki CRM. Some suppliers such as Bkav, FPT, VDC, NEO, only provide individual services on office management, human resources, customer relationship.

According to a 2015 survey of VietNam ICT Outlook in the market of Vietnam, 3\% of organizations and businesses said that they do not have a plan to deploy cloud services, $25 \%$ of businesses are studying, researching and evaluating but have no plan to use, $8 \%$ of businesses will use cloud services after 6 months, $39 \%$ of businesses are using cloud services and $19 \%$ of businesses are using cloud services and will increase usage. Vietnam is also the country with the highest cloud spending (64.4\%/year) in 2018, and higher than the average of ASEAN countries $(49.5 \%)$ and the world $(42.5 \%) .$. However, in absolute numbers, Vietnam's cloud spending is very low, only US \$ 1.7 / year in 2018; 107 times lower than Singapore; 6.5 times that of Malaysia; 2.4 times that of Thailand; and 1.3 times that of the Philippines.

Based on the 2018 report of the Asian Cloud Association, Vietnam reached 41/100 points and became the 14th country in the ranking of cloud service coverage. This shows that cloud models are becoming more popular and are starting to prevail over traditional IT models. 
Fig-4. The ranking of cloud service coverage of VietNam in the world in 2018

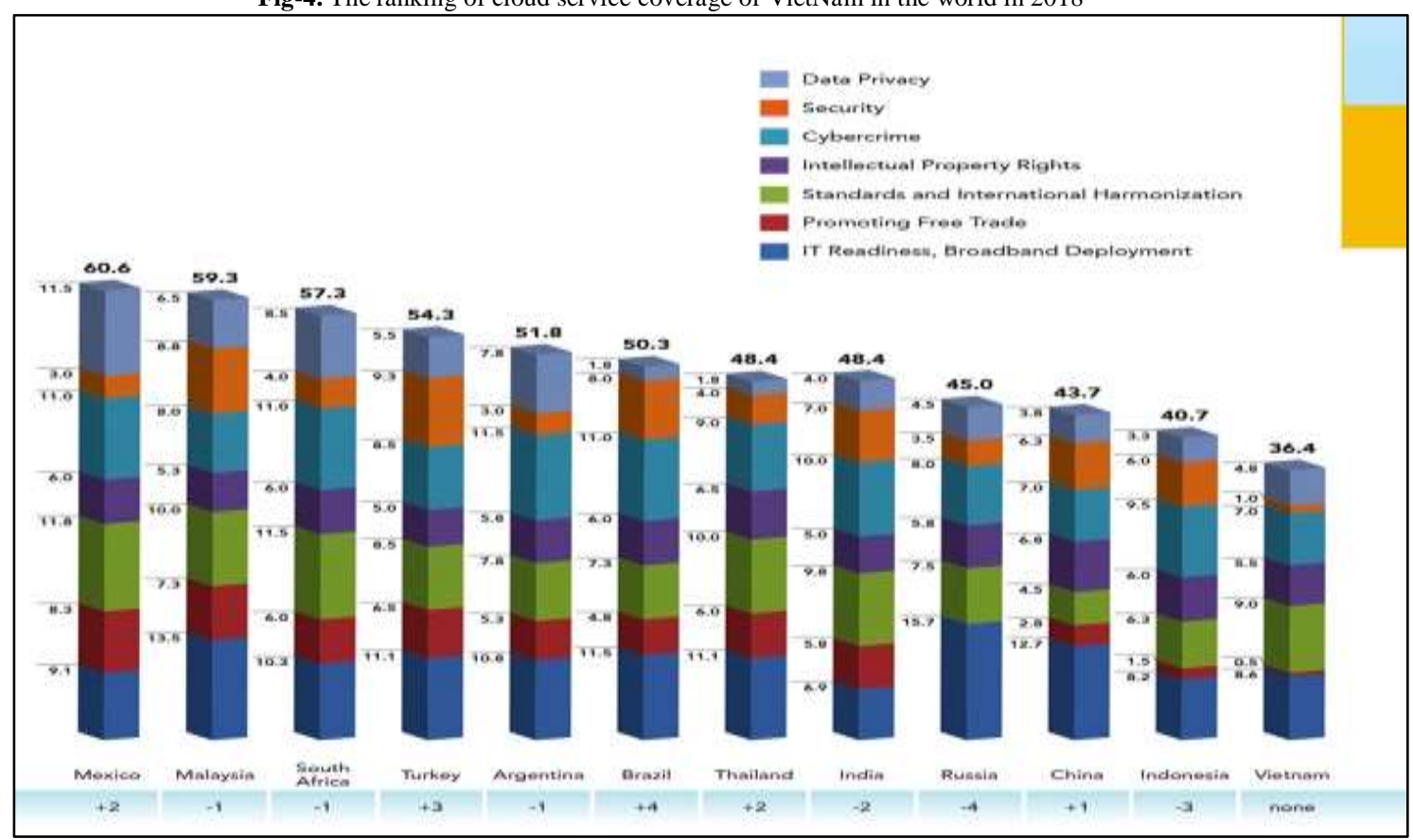

Source: The 2018 report of the Asian Cloud Association

In general, cloud computing has been gradually concerned by Vietnamese businesses, but there are still many challenges in implementation:

The first challenge to mention is the awareness of cloud computing of enterprises: Currently, enterprise administrators still do not have enough awareness and understanding of cloud computing. Besides is the concerns about being dependent on the service provider. All data, information of businesses, especially accounting information are located "on the cloud" and are managed by suppliers and businesses can not be proactive in ensuring the confidentiality of those information. Cloud computing model was developed based on 3 basic elements including central computer, server/client and web application, but the nature of these 3 components has security issues. In the case of "cloud" being attacked, the possibility of losing and occupying data is completely possible and detrimental to enterprises.

The second challenge is the availability of systems and the risk of business continuity is also one of the main challenges when applying cloud computing. This problem is explained that software running on cloud computing needs a prerequisite of connecting to the Internet. Accordingly, business operations may be interrupted when there are situations of disconnection or poor data transmission speed is also an obstacle for the application of cloud-based software, including accounting software. Besides, data security and the legal corridor are also an issue that businesses express their concerns. The fact that all enterprise data is in the "cloud" makes them wonder about information risks from suppliers. On the other hand, risks from users, user habits can also affect the data security of enterprises.

The third challenge is the concern of businesses about the ability to use services. When businesses depend on the cloud computing environment, if the service provider stops providing services at any time, the enterprise will not be able to access the services and data during those periods, affecting general work. Unstable transmission speed may be one of the major reasons why businesses do not want to completely switch to cloud computing, because if there is a problem with the transmission line, the transmission line breaks suddenly, the damage on production will be difficult to foresee.

\section{Discussion}

Although there are still challenges and difficulties affecting the application of cloud computing, but above all, it is the positive impact of this application on the activities of enterprises in general and accounting activities, in particular. In the inevitable development trend, businesses will have to gradually deploy to use cloud computing and to accelerate this process, it requires the attention and coordination of related parties. Specifically:

For the government: it is necessary to introduce laws and documents regulating binding conditions for service providers in ensuring the quality of services provided, security and responsibility when having incident occurred affecting businesses... On the other hand, priority policy for cloud computing is needed as a strong catalyst to enable digital transformation through big data and IoT applications to reach out to prioritize the development of IT infrastructure, especially broadband connectivity and cloud computing applications to a certain level to enable internal resources and achieve long lasting growth.

For the businesses: Administrators need to change awareness of cloud computing, understand the great benefits that it brings to plan applications. Accelerating the access and cloud computing applications in their business' activities because this is an inevitable trend, especially when the Industrial Revolution 4.0 and its impact on operations. 
Administrators need to put their faith in the supplier. In addition, depending on the current situation and featuress of your business, you can choose the type of service as well as how to deploy cloud computing in accordance with the actual conditions of financial capacity, human resources. .. of your business. On the other hand, accountants also need to catch this trend and at the same time broaden the knowledge and skills necessary for these services to catch up and meet the work requirements in the technology era.

\section{Conclusion}

The 4.0 technology revolution has been affecting all fields and accounting is not an exception. The application of new technologies, especially cloud computing, has and will drastically change the accounting field. Information quality of accounting information system when applying technology will become faster, more timely and more accurate, integrated information will be more diverse and extensive. This will help administrators get multidimensional and extensive information when conducting analysis and making decision in business. For Vietnamese enterprises, the application of cloud computing still has certain challenges due to many factors but in the future this will still be the inevitable trend. Therefore, to be able to accelerate the application process to occur faster, contributing to improving the operational efficiency of businesses requires each enterprise itself as well as the Government to take appropriate measures.

\section{References}

Abdullah Mohammad Al-Zoubi (2017). The effect of cloud computing on elements of accounting information system. Global Journal of Management and Business Research, 17(3): 1-8.

Ashok Kumar, G. and Pragya, G. (2018). Impact of cloud computing on accounting: Aids, challenges and its future growth. EPRA International Journal of Economic and Business Review, 6(3): 49-53.

Chan, W., Leung, E. and Pili, H. (2012). Enterprise risk Management for cloud computing, Committee of sponsoring organizations of the Treadway commission (COSO). Crowe Horwath LLP.

Ebenezer, E. E. S., Omane-Antwi, K. B. and Kyei, M. E., 2014. "Accounting in the cloud: How cloud computing can transform businesses, the ghanaian perspective." In Proceedings of the Second International Conference on Global Business, Economics, Finance and Social Sciences (GB14Chennai Conference) ISBN: 978-1941505- 14-4 Chennai, India 11-13 July 2014

Shaban, M. and Ali, M. (2014). Effect of cloud computing in accounting and comparison with the traditional model. Research Journal of Finance and Accounting, 5(23): 104-13. 